\title{
O olhar da cardiologia: Francisco Laranja e as pesquisas sobre a doença de Chagas
}

\author{
The cardiological perspective: Francisco Laranja and research \\ on Chagas' disease
}

\author{
Entrevista com/Interview with \\ Francisco Laranja \\ Concedida a/Interview given to \\ Rose Goldschmidt, Jaime \\ Benchimol, Marcos Chor \\ Maio \\ Apresentacão e edição/ \\ Presentation by \\ Wanda Hamilton \\ Pesquisadora da Casa de Oswaldo \\ Cruz/Fundação Oswaldo Cruz \\ Avenida Brasil, 4036/401 \\ 21040-361 - Rio de Janeiro - RJ - \\ Brasil \\ wandash@fiocruz.br
}

LARANJA, Francisco. O olhar da cardiologia: Francisco Laranja e as pesquisas sobre a doença de Chagas. Entrevista concedida a Goldschmidt, R.; Benchimol, J. e Chor Maio, M. Apresentação: Hamilton, W. História, Ciências, Saúde - Manguinhos, Rio de Janeiro, v.16, supl.1, jul. 2009, p.95-114.

\section{Resumo}

Francisco Laranja aproximou-se da cardiologia quando esta era ainda uma especialidade incipiente na medicina brasileira. Perito em eletrocardiografia, ele é reconhecido no panorama científico nacional e internacional pelas pesquisas que resultaram na caracterização clínica do quadro cardíaco dos casos crônicos de doença de Chagas, realizadas em Bambuí ao longo da década de 1940. Em seu depoimento, concedido à Casa de Oswaldo Cruz em 1986, Laranja discorre sobre a constituição do campo da cardiologia e da eletrocardiografia no Brasil, seu trabalho no Instituto de Aposentadoria e Pensões dos Industriários, sobre as pesquisas realizadas em Bambuí e sua gestão como diretor do Instituto Oswaldo Cruz.

Palavras-chave: história da ciência; doença de Chagas; cardiologia; Instituto Oswaldo Cruz.

\section{Abstract}

Francisco Laranja began working in cardiology when this was yet a fledgling specialty in Brazilian medicine. An expert in electrocardiography, he has gained national and international renown for his research conducted in Bambui in the 1940s, which led to the clinical characterization of the cardiac profile of chronic cases of Chagas' disease. In this interview, Laranja talks about the development of the field of cardiology and electrocardiography in Brazil, his work at the Institute of Retirement and Pensions for Industrial Workers, his research in Bambui, and his term as director of the Oswaldo Cruz Institute.

Keywords: history of science; Chagas' disease; cardiology; Oswaldo Cruz.

Recebido para publicação em dezembro de 2008.

Aprovado para publicação em maio de 2009. 
Francisco Laranja

$\mathrm{F}$ rancisco da Silva Laranja Filho é reconhecido, no panorama científico nacional e internacional, pelas pesquisas que resultaram na caracterização clínica do quadro cardíaco dos casos crônicos de doença de Chagas, realizadas em Bambuí, pequena cidade no oeste do estado de Minas Gerais, ao longo da década de 1940. Além de inúmeros artigos sobre esse tema, publicou, em 1956, em coautoria com Emmanuel Dias e Genard Nóbrega, um dos trabalhos mais citados na literatura sobre doença de Chagas, na prestigiosa revista norte-americana Circulation.

Laranja nasceu em 28 de setembro de 1916, em Garruchos, distrito do município de São Borja, no Rio Grande do Sul. Seus pais, fazendeiros da região que também se dedicavam a atividades comerciais, mudaram-se para São Borja em 1919. Quinto filho de uma família de sete irmãos, dividia seu tempo entre a fazenda e a cidade de São Borja, onde realizou seus primeiros estudos. Completou sua formação escolar em Uruguaiana e Porto Alegre, onde ingressou, em 1935, na Faculdade Federal de Medicina. Transferiu-se para o Rio de Janeiro em 1937, concluindo o curso de medicina em 1940 pela Universidade do Brasil, atual Universidade Federal do Rio de Janeiro (UFRJ).

Em 1938, portanto ainda acadêmico, prestou concurso público para a vaga de auxiliar administrativo no recém-criado Instituto de Aposentadoria e Pensões dos Industriários (IAPI) e, a partir do ano seguinte, mediante novo concurso interno para auxiliar técnico destinado a médicos e estudantes de medicina do quadro da instituição, foi designado para trabalhar em eletrocardiografia no consultório de Edgar Magalhães Gomes, a quem passou a ajudar nas perícias dos segurados que requeriam licença ou aposentadoria por problemas médicos. Por serem as doenças cardíacas as principais causas de incapacidade temporária ou invalidez, o IAPI montara um serviço de cardiologia que, segundo Laranja, era o melhor do Rio de Janeiro, tanto do ponto de vista técnico quanto clínico. Além de possuir o mais moderno eletrocardiógrafo, a instituição contava com a maior estatística de cardiologia da cidade.

O crescente interesse de Francisco Laranja pela cardiologia, campo que surgia como especialidade no Brasil e passava por importantes avanços no cenário internacional, fez com que sua parceria com Edgar Magalhães Gomes, professor da Faculdade de Medicina do Rio de Janeiro, se ampliasse para além das atividades desenvolvidas no IAPI: tornou-se seu assistente na faculdade, encarregando-se também da parte de eletrocardiografia dos cursos que Magalhães Gomes oferecia, junto com Oscar Ferreira, na Santa Casa da Misericórdia desde 1940. No ano seguinte, Laranja assumiu o cargo de médico cardiologista concursado do IAPI.

Foi em 1943 que Francisco Laranja conheceu Emmanuel Dias, diretor do recém-criado Centro de Estudos e Profilaxia da Moléstia de Chagas (CEPMC), extensão do Instituto Oswaldo Cruz (IOC) em Bambuí, que assistia ao curso de cardiologia. O estudo clínico das formas crônicas da doença de Chagas constituiu uma das prioridades de pesquisa do CEPMC, devido às dúvidas lançadas, na década de 1920, sobre a definição clínica da enfermidade e também em razão das dificuldades enfrentadas na verificação parasitológica nessa fase da infecção. Laranja, que já havia examinado mais de cinco mil doentes cardíacos no IAPI e estava atualizado quanto aos avanços que marcavam a cardiologia - especificamente a eletrocardiografia, técnica ainda incipiente na época -, era o reforço que Dias procurava 
para enfrentar os desafios da pesquisa clínica em doença de Chagas e superar as dúvidas existentes sobre o assunto. ${ }^{1}$

Terminado o curso, Dias foi procurá-lo em seu consultório particular, que na época já gozava de grande prestígio, e lhe propôs que examinasse um grupo de doentes no Hospital Evandro Chagas, em Manguinhos. Laranja examinou-os e, após verificar que se tratava de portadores de cardiopatia diferente daquelas que já havia visto no IAPI, entusiasmou-se com o desafio. Dirigiu-se a Bambuí levando seu eletrocardiógrafo e, depois de um mês examinando diversos doentes crônicos, confirmou o caráter atípico das alterações eletrocardiográficas. Iniciava-se assim a participação de Laranja junto ao IOC, instituição que o requisitaria oficialmente em 1947 para dedicar-se exclusivamente à pesquisa clínica em doença de Chagas.

Francisco Laranja era afilhado de batismo de Getúlio Vargas e amigo de João Goulart desde os tempos de escola, tendo se tornado, mais tarde, seu médico particular e conselheiro. Essas relações pessoais tiveram papel importante na escolha de seu nome para diversos cargos públicos nas décadas de 1950 e 1960. De fato, durante o governo Getúlio Vargas, Francisco Laranja foi indicado para ocupar a direção do IOC. Empossado em janeiro de 1954, sua gestão destacou-se pela organização do Conselho Deliberativo, constituído pelos chefes de Divisão, inaugurando assim o sistema colegiado para a solução de problemas gerais da administração tecnocientífica. Essa experiência durou pouco menos de um ano, sendo finalizada quando Laranja foi substituído por Antônio Augusto Xavier em fevereiro de 1955, durante o governo de Café Filho.

Em 1956, na gestão de Juscelino Kubitschek, Francisco Laranja foi indicado pelo vicepresidente João Goulart para a direção do Serviço de Assistência Médica Domiciliar de Urgência (Samdu), onde buscou viabilizar a política de expansão e interiorização dos serviços assistenciais multiplicando o número de postos nas áreas rurais. Em 1961, no início do governo Jânio Quadros, foi exonerado.

No início do mandato presidencial de João Goulart assumiu então a presidência da Companhia Urbanizadora da Nova Capital (Novacap), criada por Kubitschek e por ele encarregada da construção de Brasília. Foi destituído do cargo pouco antes do golpe militar de 1964, quando retornou às funções de médico cardiologista do IAPI, onde se aposentou em 1971, ano em que se tornou professor titular de cardiologia da Faculdade de Ciências da Saúde da Universidade de Brasília.

Em 1977, durante a gestão de Vinicius da Fonseca como presidente da Fundação Oswaldo Cruz, Francisco Laranja retornou à instituição e desenvolveu projeto de pesquisa experimental em terapêutica da doença de Chagas, no qual trabalhou até sua morte, em 1989.

Wanda Hamilton 
Francisco Laranja

Doutor Laranja, onde o senhor nasceu e realizou seus primeiros estudos?

Eu nasci em 28 de setembro de 1916, em um distrito do município de São Borja, Rio Grande do Sul, que se chama Garruchos. Toda a minha família é de fazendeiros. Fui criado na fazenda, com aquela liberdade, sem medo, e com a responsabilidade de cuidar dos animais. Isso é muito benéfico à personalidade. Quando eu tinha três anos, meus pais se mudaram para São Borja. Até os nove anos eu estudei lá. Depois, fui mandado como interno para o Colégio Santana, que era de irmãos maristas, em Uruguaiana. Estudei lá até o segundo ano ginasial e completei os estudos no Ginásio Nossa Senhora do Rosário, em Porto Alegre. Já nessa fase, eu era um menino com mentalidade de adulto. O vestibular era no fim de fevereiro. Então, entre dezembro e fevereiro, estudei somente para o vestibular. Paguei dois cursos com professores particulares, um de química e outro de português.

\section{O senhor tinha vontade de estudar, de fazer um curso universitário?}

É, eu tinha desejo de estudar, queria ser engenheiro. Depois, fui me meter a ser médico. Sabe que eu nunca entendi por que fui estudar medicina? No ginásio, não tinha nenhuma ligação com as ciências biológicas, que eram mal ministradas. Talvez tenha uma razão: era chique ser médico. Todo mundo queria ter um filho médico. Mas eu não tinha vocação para ser médico, coisa que depois se comprovou. Eu era um dos melhores cardiologistas, tinha um futuro belíssimo, ganhava uma dinheirama. Abandonei isso tudo para estudar doença de Chagas. Veja você: era vantagem? Ninguém entende. Tinha uma clínica grãfina, cobrava o que bem queria e larguei isso tudo para vir para Manguinhos, para não ganhar nada.

\section{O ingresso na Faculdade Federal de Medicina de Porto Alegre era difícil naquela época?}

Fiz vestibular em 1935 e já era muito competitivo, muita gente 'sobrava'. Entrei para a faculdade, mas continuei estudando português e tomei um curso de inglês. Eu fico bobo: o que me deu na cabeça de tomar um curso de inglês? Naquela época, os livros de medicina eram todos em francês. Você não encontrava um médico que soubesse inglês; só liam em francês. Além do curso de português e de inglês, ainda fiz um curso de datilografia na Escola Remington.

\section{O senhor era cheio de iniciativas!}

Tudo isso tinha uma finalidade: eu queria me preparar para fazer um concurso, para ganhar um emprego. Sabe qual era o concurso que eu tinha em mente? Taquígrafo da Assembleia Legislativa; ganhava um dinheirão. Então fiz o curso de datilografia e o curso na Sociedade Taquigráfica. No curso médico, não me interessava o que estava estudando, só me interessava tirar as notas para passar nos exames, porque era uma exigência legal. Eu estudava inglês, português e taquigrafia - era o que me interessava.

\section{O que fez o senhor se mudar para o Rio de Janeiro?}

O governador do Rio Grande do Sul era o José Antonio Flores da Cunha. Iam abrir concurso para taquígrafo da Câmara. Estudei bem português, era um bom taquígrafo, bom datilógrafo, estava preparado. Estava certo de que ia passar, mas quando chegou a 
hora, nomearam por pistolão. Eu fiquei danado da vida! Aí, disse: "Ah, vou embora para o Rio. Lá eu tenho mais chance". Peguei o navio e vim embora.

\section{E como foi chegar sozinho no Rio de Janeiro?}

Fui um homem com tanta oportunidade na vida, tanta sorte... Era afilhado de batismo de um homem poderosíssimo, Getúlio Vargas. Imagina: houve o golpe de 1937 e o Getúlio ficou dono deste país. Eu vim para o Rio de Janeiro em dezembro de 1936. Quando fui me despedir do meu pessoal em São Borja, fui na casa do Jango e seu Vicente, o pai dele, disse: "Olha, Francisco, dá um pulo lá em Santos Reis (a fazenda de Getúlio) porque o Protásio [Vargas], o irmão mais velho, me disse que quer mandar uma carta para o Getúlio e quer que tu leves a carta". Então eu fui a Santos Reis e o doutor Protásio disse: "Ah, Francisco, tu só entrega essa carta para ele".

Eu cheguei aqui em um dia de chuva, fui morar numa pensão no Largo do Machado, onde moravam os estudantes. O Getúlio, naquela época de férias, estava em Petrópolis, veraneando no Palácio Rio Negro. Aí fui ao Guanabara, que era ali pertinho, contei para o Lutero [Vargas] que trazia uma carta para o doutor Getúlio: "Eu te levo lá em Petrópolis". Lá, depois de esperar um pouco, me fizeram entrar em um salão grande, e da porta do outro lado veio o doutor Getúlio, sorrindo: "Ô rapaz, tu ainda te lembras de mim?" Aquilo me desconcertou, fiquei todo envergonhado. O doutor Getúlio já era presidente. Todo mundo dizia: "O Getúlio é dono do Brasil". A gente ficava amedrontada. Depois, na saída, o chefe da Casa Civil me disse: "Olha, Francisco, o doutor Getúlio me disse para arranjar um emprego para ti". Quer dizer, o Protásio e o seu Vicente fizeram uma trama, sem me dizer, para pedir um emprego para o Getúlio, porque eles sabiam que eu era garoto e não tinha uma situação boa. Eu vim para o Rio de Janeiro sem recursos. O fato é que fiquei muito envergonhado. Nunca mais apareci!

Quer dizer que o senhor se afastou. Então, de que maneira resolveu o problema da sua sobrevivência?

Havia sido recentemente criado o Instituto de Aposentadoria e Pensões dos Industriários, o IAPI. Essa foi, realmente, a primeira instituição no Brasil que suprimiu completamente a influência do pistolão e abriu concurso público para todos os cargos que deveriam ser criados, em todos os níveis. Inscrevi-me no concurso para auxiliar administrativo, me classifiquei e pronto.

O senhor fez o concurso do IAPI em que ano?

Em novembro de 1937. Fui chamado em 1938, quando ainda cursava o quarto ano de medicina. Sou funcionário da Previdência Social desde 1938, mas só ingressei como médico em 1941.

Qual era seu horário de trabalho no IAPI?

De meio-dia às seis da tarde. Seis horas por dia. Quando fui trabalhar, padeci um pouco, porque o IAPI era muito rigoroso. Se alguém chegasse dez minutos atrasado, cortavam o ponto. 
Francisco Laranja

O senhor ainda estava cursando a Faculdade de Medicina. Perdeu muitos cursos por causa do trabalho?

Ah, tinha aula nesse horário. Perdi muito. Mas acontece que, em compensação, na faculdade, o importante era fazer os exames.

O senhor poderia falar um pouco sobre o concurso interno do IAPI para auxiliar técnico?

No começo de 1939 , os poucos médicos que haviam sido admitidos no concurso já estavam um pouco sobrecarregados de trabalho. Foi então que se criou a carreira de auxiliar técnico, destinada aos médicos que eram funcionários comuns da administração. Havia muitos que não haviam prestado concurso para médico propriamente, então organizaram um concurso interno, entre médicos e estudantes de medicina, que teriam a função de ajudar os médicos concursados a realizar as perícias. Felizmente eu passei no concurso e fui designado para trabalhar em eletrocardiografia com o professor Edgar Magalhães Gomes. Esse fato de ter sido aproximado pelo destino ao professor Magalhães Gomes marcou minha carreira profissional.

Quais eram as atribuições dos médicos e dos auxiliares do IAPI?

Naquela época, o Instituto dos Industriários não proporcionava assistência médica, de forma que os médicos realizavam apenas perícias médicas para avaliar a capacidade de trabalho dos operários segurados. Mas essa perícia médica era realizada de uma maneira muito consciente, muito minuciosa.

O médico preenchia uma observação clínica muito detalhada, estabelecia um diagnóstico, pedia os exames complementares. Tudo isso era feito de maneira muito tranquila. Tanto que, no expediente diário, o médico examinava apenas seis doentes. Na minha condição, eu fazia apenas dez eletrocardiogramas por dia, montava os traçados e os entregava ao professor Magalhães Gomes. Eu tinha muita curiosidade e estudava muito eletrocardiografia, e não se passaram mais do que poucas semanas para que, além de fazer o eletrocardiograma, eu arriscasse também uma interpretação dos traçados e os mostrasse ao professor. Ele simplesmente concordava ou não, e assinava os laudos da eletrocardiografia. Bom, aquilo se desenvolveu de tal maneira que, em pouco tempo, também passei a examinar os doentes. No final do quinto ano, eu não só realizava os eletrocardiogramas e os laudos de interpretação, como elaborava as observações clínicas do professor Magalhães Gomes. Com isso, em 1939 e 1940, pude examinar um número considerável de doentes de cardiologia. Para mim aquilo representou, realmente, todo o meu aprendizado. Eu nunca tive, na faculdade, oportunidade tão extraordinária como essa de contar com a assistência de um professor como o Magalhães Gomes e, ao mesmo tempo, dispor daquele material humano para formar uma experiência extraordinária em matéria de diagnóstico cardiológico.

Nessa época, quais eram as doenças mais frequentes entre os segurados?

Bom, a grande massa de incapacitados devia-se, primeiro, a hipertensão arterial; segundo, arterioesclerose; terceiro, cardiopatia reumática; quarto, lesões sifilíticas. Eram essas as quatro grandes causas. Isso teve muita importância para o estudo que eu faria posteriormente sobre doença de Chagas. Eu tinha muita experiência, examinava centenas e centenas de 
operários. Quando examinei os primeiros casos da doença de Chagas, aquilo foi chocante, em face do padrão de doenças que eu estava acostumado a ver diariamente. Foi muito fácil verificar que estava diante de outra condição, que não era aquilo que eu estava acostumado a ver no IAPI. Isso me chamou logo a atenção. Naquela época não havia essa migração de pessoas do campo para a cidade, de forma que os operários, na sua maioria, eram pessoas nascidas na cidade mesmo, onde não havia a doença de Chagas.

Qual a importância do IAPI para o campo da cardiologia na época?

Naquela época eram raros os serviços de cardiologia propriamente, a cardiologia era exercida pelos clínicos, não havia quase especialistas nessa área. O primeiro concurso público que admitiu cardiologistas foi o do IAPI. Foi o primeiro que institucionalizou a cardiologia.

Isso pode ser entendido como causa da grande incidência de doenças cardíacas entre os segurados?

Entre as causas de incapacidade temporária ou de invalidez, no IAPI, estavam em primeiro lugar as doenças cardíacas, o que justificou a criação da especialidade. Os dois cardiologistas do Instituto, no Rio de Janeiro, eram o Magalhães Gomes e o Luis Feijó, dois professores eméritos da Universidade do Brasil. Por aí você vê o gabarito daqueles médicos que haviam sido admitidos por concurso.

Esses médicos, que estavam também vinculados à universidade, desenvolviam pesquisa na área médica?

Não tinha pesquisa na área médica. A pesquisa no Brasil se limitava, praticamente, a uma instituição no Rio de Janeiro: o Instituto Oswaldo Cruz, que foi criado com essa finalidade.

\section{A eletrocardiografia era de uso recente no Brasil?}

O método do eletrocardiograma estava ainda começando, naquela época. Pouca gente sabia eletrocardiografia. A aparelhagem era complicada. A eletrofisiologia era ciência que engatinhava ainda. Na América, por exemplo, era pontificada na Escola de Michigan por Frank Wilson, que foi o pai da moderna eletrocardiografia. As ideias do Wilson ainda eram muito recentes; mesmo nos Estados Unidos pouca gente sabia aquilo.

O senhor ainda fez mais um concurso no IAPI, dessa vez para o cargo de médico cardiologista.

Em outubro de 1941, quando eu tinha dez meses de formado, abriram um novo concurso público do IAPI para várias especialidades, entre as quais cardiologia. Aí fui nomeado cardiologista do Instituto. O setor de eletrocardiografia do Serviço de Cardiologia do IAPI era mais bem equipado do que o da universidade e melhor do que qualquer serviço de cardiologia. O engenheiro Plínio Cantanhede, presidente do Instituto, comprou um eletrocardiógrafo de três canais, que era o máximo. Acho que era o único aqui no Rio de Janeiro, e era eu quem mexia com ele. Isso me permitiu não só fazer a eletrocardiografia para o segurado do IAPI, como também dar grande colaboração à universidade.

Quais eram suas atividades profissionais, depois que o senhor se formou?

Quando me formei era assistente do Magalhães Gomes na Faculdade e no serviço especializado da Santa Casa, que ele havia organizado em 1940. Minha vida era ir de 
Francisco Laranja

manhã à enfermaria da Santa Casa e depois do almoço, ao IAPI. E eu ainda tinha consultório particular, na Cinelândia. Lá, atendia doente com hora marcada, consulta cara. A maioria dos velhos ricos morria do coração, de forma que era uma especialidade grã-fina.

Como foi, então, que ocorreu sua aproximação com a pesquisa em doença de Chagas?

Em agosto de 1943 ministramos um curso de cardiologia na Santa Casa, e entre os ouvintes estava o Emmanuel Dias, que era de Manguinhos. O Emmanuel já era um homem muito conhecido, um protozoologista de renome internacional. O Amilcar Vianna Martins havia descoberto casos agudos de doença de Chagas em Bambuí, pequena cidade no oeste mineiro, então se sabia que aquela era uma zona endêmica de Chagas. Fato é que durante a Segunda Guerra Mundial ocorreram grandes progressos na química de inseticidas, e o Emmanuel foi dirigir o posto do IOC em Bambuí, principalmente para testar a eficácia dos inseticidas no combate ao barbeiro.

Quando acabou o curso, ele foi ao meu consultório e me explicou a história de Chagas e do posto de Bambuí, e eu me interessei. Na faculdade, na cadeira de parasitologia, aprendíamos que tinha um tal de Trypanosoma cruzi. Via-se no microscópio, mas eu nunca tinha visto nenhum caso de doença de Chagas. Era uma época em que quase ninguém falava em doença de Chagas, ninguém sabia, ninguém tinha visto um caso. Era a tal doença que existe, mas ninguém viu. Alguns tinham visto casos, com o próprio doutor Chagas, mas depois aquilo caiu em descrédito tão grande que ninguém falava em doença de Chagas.

Por que caiu em descrédito? O senhor pode nos contar essa história?

É um problema muito complexo. Vou tentar resumir. O doutor Chagas descobriu e descreveu a doença em uma região do interior em que havia uma patologia muito complicada, muito complexa. Havia muitas doenças infecciosas e parasitárias, uma patologia realmente muito intrincada. Além disso, a própria doença de Chagas é extremamente complicada. Ele descreveu a doença na fase aguda, não houve problema nenhum, nunca foi contestado. Isso é importante. Dizem: "Ah, negaram a própria existência da doença de Chagas". Não; nunca ninguém negou que existisse a doença aguda. Não havia possibilidade de negar a forma aguda, porque, ao examinar o sangue de uma criança doente ao microscópio, via-se o Trypanosoma cruzi. Ninguém podia contestar aquilo. $\mathrm{O}$ agente causador da doença era demonstrável. Mas as formas crônicas foram contestadas. Por que razão? Passados uns três ou quatro meses da fase aguda, já não se encontra mais o Trypanosoma no sangue, e passados alguns anos já não se encontra o parasito nem na autópsia. Entre as formas crônicas, Carlos Chagas descreveu várias formas endócrinas, entre elas o bócio endêmico. Esse foi o motivo do descrédito, porque se demonstrou que o bócio existia em áreas onde não havia Trypanosoma. O bócio não tinha nada a ver com a doença de Chagas.

Pelo fato de não se conseguir demonstrar a existência do parasito e pelo fato de haver essas discordâncias todas nas formas crônicas, caiu muito a importância da doença. Mesmo porque os casos agudos eram muito raros. Era muito difícil um médico, mesmo nas zonas endêmicas, encontrar um caso agudo de Chagas. Tanto é que os casos de literatura podem ser contados; são casos que se publicavam um por um. Surgiram os trabalhos de Salvador Mazza na Argentina, que a partir de 1926 encontrou muitos casos agudos. No final de vinte 
anos de trabalho, Mazza conseguiu reunir mil casos agudos. Era muito trabalhoso formar uma casuística volumosa de casos agudos, dependia de muitos anos em zona endêmica.

Então, a forma aguda nunca foi contestada. O que se contestava era, realmente, a importância da doença. Se os casos eram tão raros, que importância podia ter essa doença que ninguém via? Era uma doença que ninguém via; existia, mas ninguém via.

O senhor ainda acompanhou essa discussão, na época em que foi trabalhar com doença de Chagas?

Praticamente não. Quando comecei a estudar a doença, na década de 1940, o que havia era só descrença. Com a morte do Chagas, em 1934, foram esquecendo aquilo. A doença parecia ser muito rara, porque só buscavam os casos agudos. Era uma questão de orientação da pesquisa. Os pesquisadores interessados eram parasitologistas, foi o período parasitológico da doença. Para demonstrar que o doente tinha doença de Chagas, era preciso encontrar o parasito no seu sangue, e como nos casos crônicos não se encontravam os parasitos, os parasitologistas não se interessavam pelos casos crônicos. E esses eram os casos complicados, eram da área de domínio clínico e não do parasitológico. Então se compreende o papel de Bambuí: tirar a doença do período parasitológico e colocá-la no período clínico-imunológico. A doença crônica tinha que ser estudada do ponto de vista clínico.

Estudar os casos crônicos de doença de Chagas do ponto de vista clínico foi uma das preocupações fundamentais da experiência de Bambuí?

Não era, isso foi acidental, foi um subproduto que se tornou, depois, o produto máximo. A preocupação inicial do posto de Bambuí era estudar uma forma de profilaxia. Porque, independentemente do questionamento clínico da doença, era indiscutível que os milhões de cafuas que existiam no interior eram extremamente ricos em barbeiros infectados. A aplicação dos inseticidas, se desse resultado, seria um grande benefício para as populações rurais.

Como se estabeleceu a parceira de trabalho entre o senhor e Emmanuel Dias?

Emmanuel trouxe um grupo de doentes para o Hospital Evandro Chagas, em Manguinhos. Eu os examinei, e dois doentes me chamaram muito a atenção: eles tinham uma enorme cardiopatia, algo completamente diferente de tudo o que eu tinha visto naqueles anos, nos mais de cinco mil casos examinados, tanto no IAPI quanto na Santa Casa. Foi então que me interessei e fui a Bambuí.

O senhor trabalhou intimamente com o doutor Emmanuel Dias. Pode falar um pouco sobre ele?

Emmanuel era um homem extraordinário. Afilhado do doutor Chagas, tinha trabalhado com ele em doença de Chagas no IOC. Ia sempre a Lassance. Depois, quando se formou, fez a tese sobre o Trypanosoma cruzi. Era de um entusiasmo extraordinário para trabalhar.

\section{Foi ele quem o entusiasmou a trabalhar com doença de Chagas?}

Ele entusiasmava. Já era um homem de experiência, então conhecia as pessoas, sabia avaliar um pesquisador. E notei logo que ele tinha confiança absoluta no que eu dizia. Isso era fundamental! Emmanuel era um homem simples, ia lá para o meio do mato, tinha 
intimidade com os matutos do interior. Tudo era de igual para igual. Todo mundo gostava dele. Outro componente da nossa equipe era o clínico Genard Nóbrega. Era uma figura um pouco diferente, fazia o tipo de médico sacerdote. Parecia um padre; todo mundo, quando tinha problema, ia falar com o Nóbrega. Era aquela bondade em pessoa, aquele sossego, aquela tranquilidade de espírito, compreendeu? Ele encampava o problema de todo mundo. Da equipe médica, o menos acessível era eu. Gostava mais do laboratório, embora também fizesse muita amizade com o pessoal.

\section{Como era trabalhar em Bambuí?}

O ambiente em Bambuí era interessantíssimo. A maneira de trabalhar era interessantíssima. A gente dormia ali e, em geral, comia na pensão que tinha na praça. Trabalhávamos dia e noite, também nos sábados, domingos, feriados. Eu examinava trinta ou quarenta pessoas por dia. Domingo, então, era um inferno! Aquele povo vinha da roça para a missa, depois da missa ia se consultar com a gente. Os auxiliares do posto eram recrutados entre pessoas dali mesmo, os próprios doentes se tornavam nossos auxiliares técnicos. $\mathrm{O}$ sujeito já tinha uma baita cardiopatia, e de repente: "Ah, fulano morreu ontem!". Os primeiros iam morrendo, então a gente ia trocando.

A pesquisa em doença de Chagas envolveu-o a ponto de fazê-lo afastar-se de suas outras atividades?

Ah, claro! Eu era um romântico nessa atividade; fazia porque gostava. Nunca fiz nada por obrigação ou por conveniência. E a prova é que com o decorrer do tempo e com o desenvolvimento dos estudos, abandonei praticamente a clínica, que era muito rendosa. Acontece que eu era solteiro e não tinha a ambição de enriquecer. Como é que eles dizem? "Mais vale um prazer do que um vintém". Fui a Bambuí e levei meu eletrocardiógrafo do consultório, um aparelho de corda muito sensível, um aparelho de pesquisa.

\section{O eletrocardiógrafo era portátil?}

Sim, mas era pesado, pesava mais ou menos vinte quilos. Fiquei umas três ou quatro semanas examinando os doentes. No fim desse período, voltei convencido de que aquilo era realmente uma cardiopatia diferente, que podia ser causada pela doença de Chagas. Aí começou propriamente o estudo na nossa equipe. Gernard Nóbrega, aqui no hospital, cuidava dos doentes que nós trazíamos de lá. Esse hospital vivia praticamente só para a doença de Chagas. Porque para trazer um doente, às vezes tínhamos que trazer a família inteira. E a família inteira queria dizer a mulher com seis ou oito filhos! Enchíamos o hospital!

\section{O senhor foi a primeira pessoa a pesquisar a cardiopatia chagásica, depois de Carlos Chagas?}

Não, muitas pessoas estudaram a doença. O problema foi que me impus uma metodologia diferente. Fiz questão de não conhecer a literatura para não me influenciar. Comecei da estaca zero. Eu encarava a doença como uma cardiopatia crônica, sem o parasito. Interessavame pelos caracteres dessa cardiopatia a fim de verificar se aquela exteriorização clínica era diferente, se me permitia distingui-la de outras cardiopatias. Esse foi o problema maior. Ou seja, a questão era descrever uma cardiopatia específica da doença de Chagas. 
Exato. Não era hipertensão, não era arterioesclerose, não era reumatismo, não era sífilis. Eu sabia que era outra cardiopatia. Em 1945, nós descrevemos um quadro eletrocardiográfico muito específico e convincente para a doença. Algumas características desse quadro, como a alteração do ritmo cardíaco, já tinham sido descritas pelo próprio doutor Chagas, só que ele as analisava pelo gráfico de pulso venoso, de pulso arterial, porque a eletrocardiografia, no tempo dele, praticamente não existia. Em Bambuí, naturalmente, nós tínhamos uma metodologia e um conceito novos de eletrofisiologia, então a gente pôde interpretar aquilo tudo e diferenciar perfeitamente a doença.

\section{E não houve, naquele momento, objeções como as que foram formuladas aos trabalhos de Carlos} Chagas?

Desde o primeiro trabalho publicado não houve dificuldade nenhuma. Não houve a menor objeção, nem no Brasil, nem nos Estados Unidos, nem na Europa, onde apresentamos o trabalho em várias ocasiões. Não houve a menor objeção à ideia de que aquele quadro eletrocardiográfico realmente correspondia a outra cardiopatia. Depois de estabelecido um quadro eletrocardiográfico próprio para a doença, tínhamos que descrever os caracteres clínicos específicos, a questão anatomopatológica, e as questões de ordem epidemiológica. Todos esses achados clínicos e eletrocardiográficos só se encontravam nas zonas endêmicas. Portanto, o argumento epidemiológico era convincente. Os fatos de ordem anatomopatológica tinham grande limitação, em virtude da dificuldade de se encontrar o parasito nos cortes do coração. Os pesquisadores, como estavam muito imbuídos daquele paradigma parasitológico, exigiam sempre que se demonstrasse o parasito. A dificuldade era tal, que a Divisão de Anatomia Patológica do IOC colocou um técnico só para fazer os cortes e procurar o parasito. Ele levava semanas, até meses, trabalhando naquilo. Às vezes, só depois de seiscentos cortes é que encontrava uma fibra parasitária - veja como era difícil! No nosso trabalho em Circulation, só temos 21 casos crônicos em que se encontraram os parasitos. Depois de dez anos de trabalho, tínhamos quase duzentas autópsias - material muito abundante -, no entanto o número de casos em que se encontrava o parasito era muito pequeno. Depois conseguimos reproduzir no cachorro uma cardiopatia muito parecida com a do homem. Esse argumento experimental também foi muito importante. Daí em diante nunca mais houve nenhuma objeção a respeito da cardiopatia da doença de Chagas. Foi uma página virada.

Tudo isso foi demonstrado a partir do trabalho desenvolvido em Bambuí, não é?

Sim. Quando descrevemos a parte clínica, em 1949, constatamos que alguns doentes não faziam cardiopatia nem nada - era a forma indeterminada ou latente da doença -, outros faziam o megaesôfago ou o megacólon. Os primeiros estudos sobre megacólon e megaesôfago ocasionados por doença de Chagas também foram feitos em Bambuí. Então começaram a aparecer casos por todo o Brasil.

Ou seja, uma vez identificada a doença, ela começou a aparecer no Brasil.

Exatamente. Então foi sendo vista sua dimensão. Inicialmente, fizemos uma casuística acumulada até chegar a quase quatrocentos doentes. Em nosso primeiro trabalho, diagnosticamos quase duzentos casos crônicos em Bambuí, o que correspondia a toda a literatura 
Francisco Laranja

desde 1909 até 1945. Não havia duzentos casos publicados; em um ano, identificamos mais casos do que todos os outros pesquisadores em trinta anos. Esse foi o impacto! A partir desse momento, os números já não interessavam. Começamos a examinar populações indiscriminadas e a verificar percentagens populacionais. Começamos os inquéritos em Bambuí, verificamos que $50 \%$ da população estava infectada e que a metade desses infectados tinha cardiopatia. Ou seja, praticamente $25 \%$ da população, naquela época, tinha cardiopatia chagásica! Sabia-se que as zonas endêmicas eram muito extensas, então havia razão para se suspeitar de que a doença era extremamente frequente em todas as outras áreas. Realmente surgiram muitos casos, o que confirmou que a doença era muito comum, muito frequente.

Qual é a dimensão das zonas endêmicas de doença de Chagas?

As zonas endêmicas se estendem desde os Estados Unidos até a Argentina. Mas nem toda zona endêmica tem um número considerável de casos, e nem todos os casos têm essa gravidade. Ao contrário, está demonstrado que em algumas áreas ela é muito grave, como em Bambuí, mas em outras não. O sujeito se infecta, mas o parasito quase não atinge o coração. Hoje se estudam as cepas de Trypanosoma cruzi para entender por que umas são muito cardiotrópicas e outras nem tanto.

Nessa época também foi feito um inquérito entre os empregados na rede ferroviária?

Bambuí tinha uma população muito pobre, que apresentava também outras parasitoses, e sempre surgia o argumento: "Ah, mas tem outros parasitos, isso pode alterar o quadro". Então escolhemos uma população que era praticamente de elite. Os empregados da rede ferroviária eram assalariados, tinham padrão de vida um pouco melhor. Além disso, a rede construía casinhas de alvenaria para eles, na beira da estrada de ferro. O padrão de vida deles era muito melhor do que o dos empregados de fazendas. Examinamos indistin-tamente umas trezentas ou quatrocentas pessoas e encontramos o mesmo quadro. Havia percentagem muito alta de infectados, com alta percentagem de lesões cardíacas.

Isso ocorreu porque eles já estavam infectados antes de trabalhar na rede ferroviária?

Pois aí é que está! A gente não sabia se antes de serem empregados da rede eles já estavam infectados. Talvez fosse isso, porque, naturalmente, pelas condições de moradia, deveriam apresentar um índice de infecção menor.

Em que ano foi feito esse inquérito?

O inquérito da rede foi feito em 1949. Esse foi um ano importante; coincidiu que nesse ano a Organização Pan-Americana da Saúde, a Opas, se interessou pela doença de Chagas.

\section{O interesse da Opas se deu devido à divulgação do trabalho que vocês fizeram em Bambuí?}

Não. A Opas se interessou pela doença em si, então promoveu a primeira reunião interamericana sobre a doença de Chagas em Tucumán, na Argentina, com pesquisadores da Venezuela, do Brasil, do Uruguai, da Argentina, do Chile. A delegação do Brasil, do IOC, era composta por Magarinos Torres, Emmanuel Dias e eu. Levamos esse trabalho sobre o 
inquérito da rede. Era a primeira vez que se fazia um exame indiscriminado da população com metodologia completamente diferente. Talvez tenha sido a primeira vez que se empregava uma metodologia composta pelos exames clínico e eletrocardiográfico, que eles foram usados como instrumento de avaliação de um problema de saúde pública. Hoje, os inquéritos são padronizados obedecendo-se a essas normas, a essa metodologia que foi inaugurada no inquérito da rede.

\section{Onde mais vocês divulgaram o trabalho feito em Bambuí?}

No período que se estende até mais ou menos 1953, publicamos a maioria dos trabalhos. Realmente, foi um período de muita divulgação da doença de Chagas em congressos. Houve muitos congressos internacionais a que comparecíamos e havia grande curiosidade sobre a doença, porque ela se apresentava como um problema praticamente novo, com casuística muito grande e uma importância social que se previa ser muito grande também, nos países centro e sul-americanos. Os principais congressos científicos internacionais foram o Primeiro Congresso Interamericano de Medicina, realizado em agosto de 1946, no Instituto Oswaldo Cruz; depois, as reuniões anuais da Sociedade Brasileira de Cardiologia, especialmente a segunda e a terceira, no Hotel Quitandinha [RJ], em 1945, e em Belo Horizonte [MG], em 1946, respectivamente. Nesse mesmo ano realizou-se o Congresso Interamericano de Cardiologia, no Instituto Nacional de Cardiologia do México, muito importante porque a doença de Chagas foi escolhida como um dos temas oficiais do evento, de forma que teve muito destaque, muito realce. Enquanto estávamos no México, o doutor Emmanuel Dias e eu recebemos convite da Universidade do Texas para uma série de conferências. Ficamos no Texas mais ou menos três semanas, fizemos uma série de exposições em Galveston e Houston e tivemos discussões com os médicos para ver a possibilidade do diagnóstico de doença de Chagas no sul dos Estados Unidos, onde havia extensas áreas com barbeiros infectados, mas não havia ainda casos humanos - só mais tarde é que foram encontrar alguns casos humanos nos Estados Unidos. Em 1948 dei conferências em Boston, Filadélfia, Nova York e em 1952, em Washington. Foram muitas conferências nos Estados Unidos, porque lá, quando o investigador tem uma pesquisa nova, eles chamam logo. Naquela época, pelo menos, o meio universitário americano era extraordinário, muito sério. Em 1949 aconteceu a já mencionada reunião em Tucumán. Depois, fizemos uma série de conferências em Buenos Aires sobre o problema da cardiopatia chagásica, e isso despertou o interesse dos cardiologistas argentinos. A partir daí apareceram os trabalhos, que se tornaram muito conhecidos, dos cardiologistas José Alberto Cerisola e Mauricio Rosenbaum, do Hospital Ramos Mejia.

Em Bambuí, ao mesmo tempo, foram feitas várias experiências com inseticidas. Esse método profilático teve desdobramentos? A ideia era transformar aquilo numa espécie de protótipo do que se poderia fazer nacionalmente?

Foi uma bola-de-neve. Havia os congressos médicos do Brasil Central, que reuniam principalmente os médicos do interior, e nos quais Emmanuel Dias insistia sempre sobre a necessidade do combate à doença. Em 1949, depois de um congresso desses, que ocorreu em Uberaba [MG], o Ministério da Educação e Saúde decidiu realizar uma campanha, feita 
Francisco Laranja

pelo Serviço Nacional de Malária, dirigido pelo Mario Pinotti. A experiência de Bambuí, que era praticamente um laboratório em pequena escala, já tinha evidenciado que o método de pulverização do inseticida era eficiente, eliminava o barbeiro.

Qual foi o inseticida que afinal se utilizou?

O BHC. Então bastou expandir aquela metodologia e aplicar em larga escala. Foi o que o Pinotti fez. A campanha começou em 1950, em Uberaba.

\section{Quais foram o alcance e a eficácia da campanha iniciada por Pinotti?}

Para saber a eficácia de uma campanha preventiva você tem que esperar um certo tempo. Além disso, nem sempre é fácil avaliar. Teria que haver um meio de avaliar anualmente quantos casos novos apareceram, e isso não se tinha. Em segundo lugar, seria preciso verificar se havia um tempo prolongado sem casos novos. Isso aconteceu em Bambuí: desde 1956 nunca mais apareceu caso novo, agudo. Então sabemos que a doença, ali, foi erradicada.

\section{A campanha do Mário Pinotti foi abrangente?}

Primeiro fizeram todo o Triângulo Mineiro, depois a campanha foi estendida pelo Brasil. Até que ponto ela impediu que novos casos surgissem é muito difícil de responder, mas provavelmente, se não a tivessem feito, teriam surgido milhões de casos.

\section{Mesmo depois da campanha, o Instituto Oswaldo Cruz manteve contato com Bambuí?}

Sim, além da profilaxia por inseticidas, teve também a educação sanitária. Em Bambuí, se um menino vê um barbeiro ele o reconhece, o coloca em uma caixinha de fósforo e o leva até o posto.

O senhor soube que, recentemente, houve um contágio por via oral? Os jornais afirmaram que essa forma de contágio era desconhecida.

Sim, no Rio Grande do Sul. Disseram que foi a primeira vez, mas não foi; já aconteceu antes. Na década de 1960, em Teutônia [RS], fizeram uma festa de fim de ano na Escola de Agronomia, e depois desse almoço apareceram umas oito pessoas com doença de Chagas. Parece que quatro morreram. Foi uma epidemia de doença de Chagas aguda. Não se esclareceu bem o fator epidemiológico, e restou a suspeita de contaminação por via oral.

Quais os avanços produzidos, até hoje, em relação ao tratamento dos doentes?

Eu me pergunto às vezes: será que um doente com cardiopatia chagásica está em melhores condições do que estava em 1950 ou 1960? Está, e por causa de duas instituições, nenhuma delas brasileiras. Se não fosse a Roche e a Bayer, nós estaríamos exatamente na mesma posição de trinta anos atrás. Simplesmente porque eles sintetizaram uma substância que tem uma certa ação tripanocida. Nesse sentido progrediu. Mas não foi no Brasil. Melhor seria se tivéssemos sintetizado uma dessas substâncias aqui, é claro. Quem dera tivéssemos tecnologia de ponta capaz de abordar um problema desses, a síntese de uma quimioterapia 
eficiente contra o Trypanosoma cruzi. Os outros progressos, quais foram? O mais badalado é o implante de marca-passo. Ele pode evitar a morte súbita, não tenho dúvida disso, mas é muito caro. Eu queria saber quanto se gasta em um implante de marca-passo; seria interessante empregar parte desses recursos em pesquisas voltadas para prevenir o desenvolvimento dessas lesões cardíacas, em vez de deixar que elas apareçam para então fazer um comércio da doença. Porque a verdade é esta: há aqueles que empregam os meios terapêuticos com seriedade, mas há também os aproveitadores que fabricam situações para empregá-los.

O senhor não acha que desencadear um programa preventivo contra a doença de Chagas implicaria mexer profundamente nas estruturas sociais do interior, nas condições de moradia, de salubridade, de educação?

Fazer uma campanha de erradicação da moléstia, realmente, é muito complicado. Porque mexer na própria habitação rural não basta. Tem que ter educação para a população, e para ter educação é preciso ter dinheiro e tempo. Então vem uma série de fatores que complicam. Mas não é só isso. Um programa preventivo leva muitos anos - décadas, porque avança gradativamente - até chegar aos resultados que se vê na população do município de Bambuí hoje. Então já se sabe que um programa inteiramente eficaz é tarefa para décadas, mas isso não implica que a pesquisa científica não deva esclarecer sobre os aspectos que podem conduzir à prevenção, os fatores responsáveis pela formação da cardiopatia crônica ou dos megas. Alguns problemas devem ser encarados com certa prioridade. A tendência do pesquisador, especialmente quando ele visa à formação do currículo, à publicação de trabalhos, é pegar os aspectos que são mais exequíveis. Pesquisas mais difíceis, em geral demoram muito; essas o pesquisador não quer fazer.

O senhor foi diretor do Instituto Oswaldo Cruz em 1954. Como foi sua escolha para esse cargo?

Quando se criou Ministério da Saúde, com o desdobramento do Ministério da Educação e Saúde em dois ministérios, o governo decidiu substituir o diretor do Instituto Oswaldo Cruz. O presidente Vargas queria que Henrique Aragão, que havia ocupado o cargo entre 1942 e 1950, retomasse a direção do Instituto. Mas o doutor Aragão, mesmo insistentemente convidado, não aceitou porque se sentia cansado - ele já estava com 76 anos. Com a negativa, foi pedido a ele que indicasse uma lista de três nomes. Ele fez a indicação do doutor Heráclides de Souza Araújo, do doutor Emmanuel Dias e a minha. De posse dessa lista, o ministro da Saúde Miguel Couto Filho consultou outros grupos de pesquisadores do Instituto e decidiu. Meu nome foi levado ao presidente Vargas e fui nomeado. Eu não tinha a menor ideia dessas démarches, porque, como não fazia parte do quadro de pesquisadores do Instituto, não me envolvia com questões de sua administração. De forma que foi uma surpresa para mim quando me chamaram e disseram que eu já havia sido nomeado diretor. Isso foi em janeiro de 1954.

Sua indicação gerou algum boato, pelo fato de o senhor ser afilhado do Getúlio Vargas?

Nada! Ninguém sabia. 
Francisco Laranja

Ninguém sabia?!

Não! Só depois da minha nomeação souberam que eu era de São Borja. Eu havia ficado dez anos no IOC fazendo pesquisa, mas não frequentara os ambientes. Era muito modesto, muito simples. Trabalhei no IOC durante alguns anos antes de me requisitarem oficialmente. O Aragão era muito cioso da responsabilidade de trazer oficialmente um pesquisador. Acho que fui um dos poucos pesquisadores de fora que o Instituto requisitou. Para o Instituto isso representava muita coisa. Então demorou muito. Eu já tinha publicado vários trabalhos, tinha ido a vários congressos e até representado o Instituto oficialmente, mas não tinha sido formalmente requisitado. Eu era um 'paraquedista', estava por minha conta.

\section{Qual era a sua visão do IOC?}

O Instituto antigamente era uma instituição muito homogênea, uma instituição de pesquisa com tradição muito bem definida e padrão muito bem caracterizado. Era, como dizem hoje, muito transparente. Tudo se sabia, embora não houvesse a comunicação que se tem hoje. Reparem na produção científica do Instituto. É só ver o padrão das Memórias do Instituto Oswaldo Cruz desde o tempo do doutor Oswaldo. Que padrão! É que o Instituto não alardeava.

\section{Qual foi o impacto da nomeação para diretor do IOC em sua vida?}

Eu estava me anulando, porque tive que me afastar da pesquisa. Não gostava, mas é aquilo: "Deus dá biscoito para quem não tem dente". Em outras ocasiões na minha vida aconteceu a mesma coisa. Acho que o azar era eu não querer - sinceramente, não gosto disso, - aí me colocavam em cargos administrativos. Eu não gostava de administrar, mas foi irrecusável. Bastava ao diretor ter um certo senso no trato com as pessoas, como eu tive. Por isso todo mundo ficou satisfeito, é claro!

O senhor se sentiu à vontade nesse jogo delicado do poder e da política?

Nunca tive nenhum fascínio, nenhuma atração pelo poder.

Mas o senhor tinha facilidade de lidar com isso?

Acho que sim. Eu sabia que devia desempenhar a função de acordo com aquilo que esperavam, a contento dos outros. Fato é que, quando fui nomeado, praticamente foi uma transição tranquila. Era muito pequeno o número de pesquisadores ou candidatos ao cargo que se viram prejudicados, esta é a verdade. Eu assumi a direção já conhecendo um pouco os problemas do IOC. Sabia que a maior aspiração do pessoal era que a diretoria não fosse tão centralizadora, que desse oportunidade aos demais técnicos para também opinar e mostrar sua presença na direção. Então organizei um sistema mais ou menos do tipo parlamentarista. Criei um Conselho Deliberativo constituído pelos oito chefes de divisão, de forma que todas as alas representativas da pesquisa estavam na direção, não simplesmente como um conselho técnico consultivo, mas como um conselho deliberativo. As decisões da diretoria eram tomadas por votação no Conselho, e isso tranquilizou o pessoal. A prova foi o apoio que me deram, quando, depois de um ano e pouco, em fevereiro de 1955, com a mudança do panorama político do país, eu saí da direção. 
Como funcionava a pesquisa no Instituto Oswaldo Cruz, na época em que o senhor foi diretor?

A estrutura de pesquisa era muito livre, porque era baseada na célula que era o laboratório. Os chefes de laboratório tinham muita autonomia. Por exemplo, para pedir um material, o sujeito não tinha que se dirigir ao chefe de divisão; pedia diretamente ao diretor. Quando criei o Conselho, os chefes de divisão, que eram figuras burocráticas, se tornaram figuras atuantes. O que importa é o poder de decisão; enquanto a pessoa não tem poder de decisão é uma figura apagada, só uma figura burocrática.

Como funcionava esse Conselho Deliberativo, criado em 1954?

As reuniões dependiam da pauta, dos assuntos. A rotina era muito suave, e os assuntos que dependiam de uma decisão coletiva eram mais raros. Marcávamos as reuniões conforme os assuntos, as matérias apareciam. O Instituto era muito tranquilo e silencioso. O diretor tinha muito tempo, e o lugar onde menos permanecia era no gabinete. O Aragão, por exemplo - e eu também fazia muito isso -, estava sempre rondando os laboratórios. Era uma tradição o diretor ir aos laboratórios para tomar conhecimento, tomar contato direto com o pesquisador, ver o problema dele diretamente. Isso se manteve.

As relações entre as divisões e seus chefes ficaram melhores depois da criação do Conselho Deliberativo?

Em uma instituição científica não se pode generalizar tanto. Os cientistas brigam muito, têm muitos ciúmes dos outros pesquisadores; são como crianças. Você nunca pode tocar em qualquer coisa que venha a ferir a vaidade do pesquisador. No político, você nunca pode tocar em qualquer coisa que venha a restringir seu domínio político, assim como você nunca pode tocar no bolso do capitalista, não é mesmo? Se você respeitar essas coisas, está tudo bem.

Na sua avaliação pessoal, quais eram as áreas mais importantes do Instituto, naquela ocasião?

$\mathrm{Na}$ minha avaliação era doença de Chagas. Qual podia ser? É claro! Como pesquisador, eu não posso fugir à regra: a minha área era a mais importante.

Os trabalhos em Bambuí continuaram enquanto o senhor foi diretor do Instituto Oswaldo Cruz?

Sim, mas não havia uma preferência particular por Bambuí. Aliás, sobre esse aspecto há uma coisa curiosa. Quando assumi, o doutor Aragão, que era meu consultor, me disse: "Laranja, agora você tem que se afastar da pesquisa. Como diretor, você não deve ser pesquisador, porque qualquer benefício que dê ao seu laboratório vai parecer abuso de autoridade, que você está se valendo do cargo de diretor para beneficiar o seu laboratório". Tanto é que me desliguei da pesquisa quando assumi a diretoria.

Mas a doença de Chagas não era estudada por outras divisões também?

Era um conjunto, mas tudo resultava de Bambuí. Havia vários outros approaches, outros enfoques, como por exemplo o de Julio Muniz, da imunologia, mas era em torno de um eixo comum: Bambuí. 
Francisco Laranja

O diretor do Instituto Oswaldo Cruz ou o Ministério da Saúde tinham autoridade para determinar os temas de pesquisa das divisões e dos laboratórios?

Não, cada um escolhia por si. Naturalmente, o pessoal tinha muito senso. Cada um tinha sua preferência por determinados assuntos de pesquisa e liberdade de fazer a que quisesse. Mas é claro que do ponto de vista, digamos, do Ministério, ou do governo, ou da própria sociedade, alguns assuntos diziam mais diretamente à coletividade. A doença de Chagas, por exemplo, era um problema à vista de todos. Outros pesquisadores, que atuavam em campos mais abstratos, nunca chegavam a despertar grande interesse do povo. Isso existe sempre e em toda parte: alguns que trabalham em um campo mais aplicado, outros que trabalham em um campo mais abstrato.

Mas esses dois campos eram igualmente aquinhoados, em termos de recursos?

Era a mesma coisa; o que importava era a qualidade do trabalho.

Essas áreas que estavam mais diretamente voltadas para as questões de saúde pública, como, por exemplo, doença de Chagas, esquistossomose, bouba, febre amarela, tinham algum tipo de prioridade em relação aos outros campos?

Elas recebiam um tratamento especial, recebiam muito apoio. Por exemplo, tinha um posto em Rio Bonito [RJ] e outro em Araruama [RJ] para combate à bouba. Eles tinham todos os meios de que precisavam e a bouba se extinguiu em pouco tempo nessas regiões. Esquistossomose e doença de Chagas também. Essas endemias recebiam tratamento muito particularizado.

O Instituto Oswaldo Cruz aproveitava os financiamentos do CNPq para desenvolver seus trabalhos?

O CNPq veio depois. As pesquisas de Bambuí, por exemplo, como todas as pesquisas até aquele período, não tinham nenhum auxílio de fora. Eu me lembro que, dos nossos trabalhos, só o último, que foi publicado em 1956 na revista Circulation, quando eu já tinha saído da diretoria, foi financiado parcialmente pelo CNPq. É o único trabalho nosso financiado por uma instituição externa ao Instituto. Todos os outros foram financiados por recursos orçamentários do Instituto Oswaldo Cruz.

Como foi a sua saída da direção do Instituto Oswaldo Cruz?

Sob o impacto político do suicídio do doutor Getúlio, em agosto de 1954, naturalmente, mudou toda a administração do país. Quando apresentei o pedido de demissão para o novo ministro, já no governo Café Filho, o pessoal do IOC apresentou um memorial solicitando ao governo que não mudasse a direção do Instituto. Eles queriam que a instituição se mantivesse isenta de influências político-partidárias, o que, aliás, tinha sido respeitado. Por essa razão puderam permanecer no cargo, durante tantos anos, todos os diretores até então. Mudou o governo, mas eu continuei, não me deram a demissão imediatamente. A exoneração só veio em fevereiro, porque surgiu um problema administrativo oriundo de uma determinação do ministro. 


\section{O senhor se afastou completamente do Instituto?}

Praticamente sim. Retornei ao IAPI. Mas ainda fui ao IOC, e com Emmanuel, Nóbrega e Miranda redigi o trabalho do Circulation, em 1955.

Como foi a experiência desse trabalho publicado no Circulation, um dos mais citados na literatura sobre doença de Chagas?

Eu tinha feito algumas conferências em Boston, em 1948, na Universidade de Harvard. Os editores do jornal eram de Harvard. Eles acharam oportuno publicar um trabalho sobre Chagas disease. O Circulation era um jornal novo, da Associação Americana de Cardiologia, mas essa entidade era o órgão máximo da cardiologia. Eles me escreveram pedindo uma revisão dos conhecimentos recentes sobre doença de Chagas, porque iam publicar uma review no Circulation. Quando veio aquele pedido, nós tínhamos tanto material original ainda não publicado, que eu disse para o Emmanuel: "Eu não vou fazer revisão; vamos fazer um trabalho original". Fizemos um trabalho completamente diferente daquilo que pediram, mas eles gostaram. O editor me disse que tinha sido analisado por todos os membros do Conselho Editorial, do staff e que tinham gostado muito. Fez um mundo de elogios e o publicaram como um dos artigos líderes daquele número. É um trabalho que teve muita importância porque foi publicado em língua inglesa - ainda mais em um journal como o Circulation, em que era muito difícil publicar; o mundo inteiro queria publicar lá. Realmente era uma oportunidade, e deu grande divulgação ao trabalho. Fazia dez anos que vínhamos publicando, mas aquele se tornou o trabalho mais conhecido. Depois dos trabalhos do doutor Chagas, até hoje é o trabalho mais citado na literatura sobre doença de Chagas.

\section{Ficha Técnica}

Local: Fundação Oswaldo Cruz, Rio de Janeiro.

Duração: 11 horas.

Data: 26/11/1986 a 17/12/1986.

Entrevistado: Francisco Laranja.

Entrevistadores: Rose Ingrid Goldschmidt, Jaime Benchimol e Marcos Chor Maio. Edição: Wanda Hamilton.

\section{NOTAS}

${ }^{1}$ Sobre a história da pesquisa em doença de Chagas ver Kropf, 2009.

${ }^{2}$ A entrevista, realizada em 1986, foi editada para fins de publicação neste número. A versão completa do documento, sob a guarda do Departamento de Arquivo e Documentação da Casa de Oswaldo Cruz (COC)/Fiocruz, integra o acervo de depoimentos do projeto Memória de Manguinhos, desenvolvido pelo Departamento de Pesquisa da COC/Fiocruz.

${ }^{3}$ Emmanuel Dias (1908-1962) formou-se pela Faculdade de Medicina do Rio de Janeiro em 1933, com tese de doutoramento sobre aspectos do ciclo evolutivo do Trypanosoma cruzi. Trabalhou como voluntário do IOC de 1929 a 1933, quando foi contratado. Era chefe da Seção de Inquéritos e Trabalhos de Campo da Divisão de Estudos das Endemias do IOC quando foi nomeado, em 1943, para a direção do recémcriado Centro de Estudos e Profilaxia da Moléstia de Chagas, em Bambuí. À frente desse posto do IOC, e com a colaboração de outros médicos e pesquisadores, realizou importantes estudos com o objetivo de desenvolver meios técnicos para a profilaxia da doença de Chagas e estabelecer a caracterização clínica da doença em sua fase crônica. Foi ativo militante da importância da doença de Chagas como problema de saúde pública no Brasil e no continente latino-americano, tendo participado de inúmeros congressos, no país e no exterior, com o objetivo de disseminar tal ideia. 
${ }^{4}$ Amilcar Vianna Martins (1907-1990) formou-se pela Faculdade de Medicina de Belo Horizonte, onde foi aprovado em concurso para livre-docente da cadeira de Parasitologia, em 1939. De 1947 a 1949 foi chefe do Serviço de Endemias Rurais da Secretaria de Saúde de Minas Gerais. Em 1952 atuou como perito em doenças parasitárias da Organização Mundial de Saúde. Entre 1956 e 1958 dirigiu o Instituto Nacional de Endemias Rurais (INERu), subordinado ao Departamento Nacional de Endemias Rurais (DNERu), estabelecido no Ministério da Saúde em 1956. Martins desempenhou papel decisivo na criação do Centro de Pesquisas de Belo Horizonte, um dos órgãos do INERu e origem do atual Instituto de Pesquisa René Rachou, da Fiocruz. Entre 1958 e 1960 foi diretor do IOC e entre 1960 e 1961, do DNERu. Em 1966 assumiu a direção do Instituto de Ciências Biológicas da Universidade Federal de Minas Gerais e no ano seguinte tornou-se diretor do Departamento de Parasitologia desse instituto. Em 1969 foi aposentado compulsoriamente pelo Ato Institucional n. 5, retornando a suas funções docentes em 1979.

${ }^{5}$ Salvador Mazza (1886-1946) formou-se pela Facultad de Ciencias Médicas da Universidad de Buenos Aires (UBA), em 1903. Em 1910, em parceria com Rudolf Kraus, desenvolvou vacina em dose única contra o tifo. Em 1916, enquanto realizava estudos na Alemanha, conheceu Carlos Chagas, que havia descoberto recentemente a tripanossomíase americana. Após período de estudos na sede do Instituto Pasteur da Tunísia com o doutor Charles Nicolle, Mazza regressou à Argentina em 1925 e foi nomeado diretor do laboratório e do museu do Instituto de Clínica Quirúrgica da Facultad de Medicina da UBA. A intenção de Mazza de fundar um instituto dedicado à investigação e ao diagnóstico das doenças endêmicas americanas concretizou-se em 1926, quando foi criada, na província de Jujuy, a Misión de Estudios de Patología Regional Argentina (Mepra), à frente da qual Mazza teve papel fundamental na continuidade dos estudos e do interesse pela doença de Chagas, tendo detectado grande número de casos agudos e demonstrado a ampla dispersão e importância médico-social da doença. Foi nessa instituição que o médico Cecilio Romaña descreveu, em 1935, o edema palpebral unilateral que caracteriza a porta de entrada do Trypanosoma cruzi nos casos agudos de doença de Chagas e que se denominou sinal de Romaña. Mazza foi o principal investigador argentino em doença de Chagas. Publicou mais de 250 trabalhos sobre diferentes aspectos da doença e participou de inúmeras reuniões científicas internacionais. Sobre a história da pesquisa e combate à doença de Chagas na Argentina, ver artigo de Juan Pablo Zabala neste número.

${ }^{6}$ Ver Dias, Laranja, Nóbrega, 1945.

${ }^{7}$ Ver Laranja, Dias, Nóbrega, 1956.

${ }^{8}$ Para a história da pesquisa sobre o megaesôfago, ver artigo de Joffre Rezende, neste número.

${ }^{9}$ Ver Dias, Laranja, Pellegrino, 1948.

${ }^{10}$ Ver Dias, Laraja, Pellegrino, 1950.

${ }^{11}$ Ver Dias, Pellegrino, 1948.

${ }^{12}$ Francisco Laranja foi requisitado oficialmente em 1947, pela direção do IOC, para se dedicar integralmente aos trabalhos sobre a doença de Chagas.

\section{REFERÊNCIAS}

DIAS, Emmanuel; LARANJA, Francisco PELLEGRINO, José.

Inquérito clínico-epidemiológico sobre doença de Chagas feito entre as estações de Iguatama e Campos Altos, Oeste de Minas. In: Primera Reunión Panamericana sobre Enfermedad de Chagas, Ops, Tucumán.1: p.33-34. 1950.

DIAS, Emmanuel; LARANJA, Francisco; PELLEGRINO, José.

Estudos sobre a importância social da doença de Chagas, 1: Inquérito clínico-epidemiológico feito nas vizinhanças de Bambuí, oeste de Minas. Brazil Medico, Rio de Janeiro, v.62, p.412-413. 1948.

DIAS, Emmanuel; LARANJA, Francisco; Nobrega, Genard.

Doença de Chagas. Memórias do Instituto
Oswaldo Cruz, Rio de Janeiro, v.43, n.3, p.495-581. 1945.

DIAS, Emmanuel; PELLEGRINO, José. Alguns ensaios com o gammexane no combate aos transmissores da doença de Chagas. Brazil Medico, Rio de Janeiro, v.62, n.18-20, p.185191. 1948.

KROPF, Simone.

Doença de Chagas, doença do Brasil: ciência, saúde e nação (1909-1962). Rio de Janeiro: Editora Fiocruz. 2009.

LARANJA, Francisco et al. Chagas' disease: a clinical, epidemiologic and pathologic study. Circulation, Dallas, v.14, p.1035-1060. 1956. 